\title{
Pemanfaatan Data Mining dalam Penentuan Rekomendasi Mustahik (Penerima Zakat)
}

\author{
Andi Abdul Malik Ahmad ${ }^{1}$, Zawiyah Saharuna ${ }^{2}$, dan Muhammad Fajri Raharjo ${ }^{3}$ \\ 1,2,3 Jurusan Teknik Elektro, Politeknik Negeri Ujung Pandang \\ *Corresponding Author, email: abdul.malik.ahmad997@gmail.com
}

\begin{abstract}
Penelitian ini menerapkan data mining dalam menentukan rekomendasi bagi mustahik. Penerapannya dilakukan menggunakan metode klasifikasi dengan algoritma artificial neural network dimana atribut yang digunakan adalah umur, dan jenis pekerjaan kepala keluarga, kondisi, dan kepemilikan tempat tinggal, tempat pembuangan kotoran, pendapatan bulanan keluarga, jumlah tanggungan, dan pola makan. Pengujian dilakukan menggunakan kombinasi nilai antara learning rate, epoch, $k$-fold, dan neuron hidden layer. Berdasarkan hasil pengujian dari proses klasifikasi diperoleh bahwa algoritma artificial neural network memiliki akurasi tertinggi pada saat jumlah neuron hidden layer bernilai enam, learning rate bernilai satu, jumlah fold tujuh, dan jumlah epoch bernilai 200, yaitu 92.09\%. Hasil pengujian ini kemudian ditampilkan pada halaman sistem informasi mustahik.
\end{abstract}

Kata Kunci: Data Mining, Artificial Neural Network, Klasifikasi, Zakat

Abstrak- This study applies data mining in determining recommendations for mustahik. The application is carried out using a classification method with an artificial neural network algorithm where the attributes used are age and type of work of the head of the family, the condition and ownership of the residence, the place of sewage, family monthly income, number of dependents, and diet. Tests are carried out using a combination of values between learning rate, epoch, $k$-fold, and hidden layer neurons. Based on the test results from the classification process, it is found that the artificial neural network algorithm has the highest accuracy when the number of hidden layer neurons is six, the learning rate is one, the fold is seven, and the number of epochs is 200 , which is $\mathbf{9 2 . 0 9 \%}$. The test results are then displayed on the Mustahik information system page.

Keywords: Data Mining, Artificial Neural Network, Klasifikasi, Zakat

() 2020 Elektron Jurnal Ilmiah

\section{I.PENDAHULUAN}

Problema kemiskinan terus menjadi masalah besar sepanjang sejarah Indonesia sebagai sebuah negara. Berdasarkan data Badan Pusat Statistik (BPS) pada Maret 2017 jumlah penduduk kurang mampu di Sulawesi Selatan sebesar 813,07 ribu jiwa $(9,38$ persen), dimana 659,51 ribu jiwa $(81,11$ persen) berada di daerah pedesaan dan 153,56 ribu jiwa (18,89 persen) berada di daerah perkotaan[1]. Jumlah itu mengalami kenaikan 4,43 ribu jiwa di daerah perkotaan dan 1,61 ribu jiwa di daerah perdesaan dibanding data pada bulan Maret 2016[2].

Islam dengan segala ajaran luhur yang terkandung didalamnya memiliki proyeksi yang jauh ke depan dengan tujuan untuk memelihara kepentingan dan kemaslahatan umat manusia. Salah satu cara yang digunakan islam untuk pengentasan kemiskanan yaitu berupa zakat.

Menurut istilah, zakat bermakna mengeluarkan sebagian harta (tertentu) yang telah diwajibkan Allah Swt untuk diberikan kepada orang-orang yang berhak menerimanya, dengan kadar, haul tertentu dan memenuhi syarat dan rukunnva. Zakat merupakan ibadah yang memiliki nilai ganda, hablum minallah (vertikal) dan hablum minannas (horizontal), dimensi ritual dan sosial, Artinya, orang yang selalu menunaikan zakat akan meningkatkan keimanan dan ketaqwaan kepada Allah SWT dan menumbuhkan rasa kepedulian sosial, serta membangun hubungan sosial kemasyarakatan[3].

Dalam pemberian zakat, penentuan seseorang bisa dikategorikan dapat menerima zakat sangat penting. Penentuan kriteria penerima zakat harus digambarkan dengan jelas agar tidak terjadi kesalahan alokasi dan penyalurannya yang pada akhirnya berdampak pada gagalnya pemberdayaan mustahik tersebut. Karena pada dasarnya orang kaya tidak boleh diberi bagian dari zakat. Hal ini adalah kesepakatan para ulama sesuai sabda Rasulullah SAW, "Tidak ada bagian darinya (harta zakat) bagi orang kaya" (Shahih. HR. Abu Daud (1633) dan An-Nasa "i (2598).

Dalam islam, zakat merupakan salah satu dari rukun islam yang dapat diandalkan sebagai mekanisme dan solusi nyata dalam mengatasi kemiskinan di Indonesia. Hal ini dibuktikan zakat semenjak zaman Rasulullah, Sahabat dan kekhalifahan berikutnya telah mampu menjadi solusi yang efektif dalam mengatasi permasalahan keumatan. Akan tetapi, keterbatasan dana setiap organisasi pengelola zakat di Indonesia mengakibatkan hanya sebagian kecil masyarakat kurang mampu yang bisa menikmati zakat. Berdasarkan hasil statistik Badan Amil Zakat Nasional (BAZNAS) tahun 2017 jumlah penerima manfaat sekitar 8,7 juta jiwa.

Untuk membantu pengelola zakat dalam mengelola dana yang dimiliki, dibutuhkan suatu mekanisme yang 
dapat memproses data mustahik agar dapat diseleksi dengan lebih capat dan tepat.

Data mining adalah suatu proses menemukan hubungan yang berarti, pola, dan kecenderungan dengan memeriksa dalam sekumpulan besar data yang tersimpan dalam penyimpanan dengan menggunakan teknik pengenalan pola seperti teknik statistik dan matematika[4].

Beberapa peneliti telah melakukan penelitian dalam bidang penanggulangan kemiskinan dengan memanfaatkan data mining. Annur (2018) melakukan penelitian menggunakan metode Naïve Bayes Classifier dalam pengambilan keputusan seseorang miskin atau tidak[5]. Wanto (2018) menggunakan metode klasifikasi jaringan saraf tiruan dalam memprediksi jumlah kemiskinan pada Kabupaten/Kota di provinsi Riau[6]. Namun kedua penelitian tersebut hanya berupa perhitungan dan pengelompokan seseorang mampu atau tidak, sehingga dibutuhkan sistem yang saling terhubung antara analisis untuk mengurutkan mustahik dan sistem informasi yang dapat mengelola data mustahik agar lebih mudah dipahami oleh pengguna dan pemberian zakat lebih tepat sasaran.

Oleh karena itu pada penelitian ini dengan metode klasifikasi dan sistem informasi berbasis web dapat menjadi decision support systems sebagai penentu kebijakan program pemberian zakat yang lebih efisien dan tepat sasaran.

\section{METODE}

Metode dalam penelitian diperlukan agar penelitian lebih terstruktur, sehingga hasil yang akan diperoleh sesuai dengan tujuan pada penelitian. Adapun tahapan metode penelitian seperti pada Gambar 1.

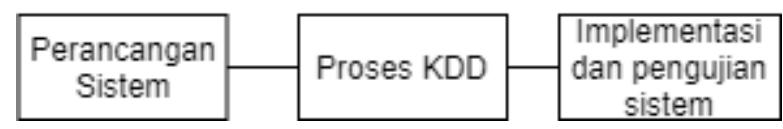

Gambar 1. Metodologi Penelitian

A. Perancangan Sistem

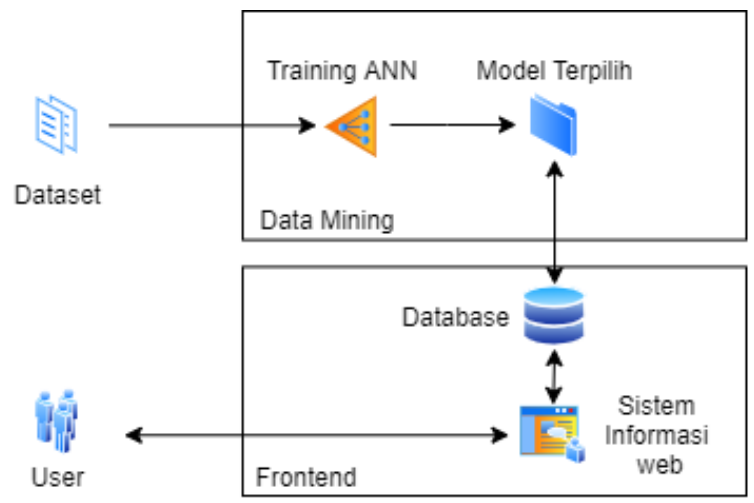

Gambar 2. Perancangan sistem

Rancangan sistem dapat dillihat pada Gambar 2. Aplikasi yang dibangun terdiri dari dua bagian yaitu data mining dan user interface/frontend. Bagian data mining adalah proses training data menggunakan bahasa pemrograman Python. Setelah training data telah selesai maka terbentuklah model yang akan digunaan untuk pengujian data mustahik.

Bagian user interface/frontend adalah sistem informasi mengguanakan platform website yang digunakan untuk meginput data keluarga dan survei. data survei akan disimpan pada database MySQL yang kemudian akan men-trigger API mengambil data tersebut untuk diklasifikasi menggunakan model terpilih. Hasil klasifikasi akan disimpan kembali ke database MySQL sehingga dapat di visualisasikan pada halaman website. Untuk usecase diagram dapat dilihat pada Gambar 3. Dimana terdapat dua jenis user yaitu surveyor yang bertugas untuk mengelola data mustahik dan staf pengelola zakat yang melihat hasil laporan rekomendasi mustahik sebagai acuan pemberian zakat.

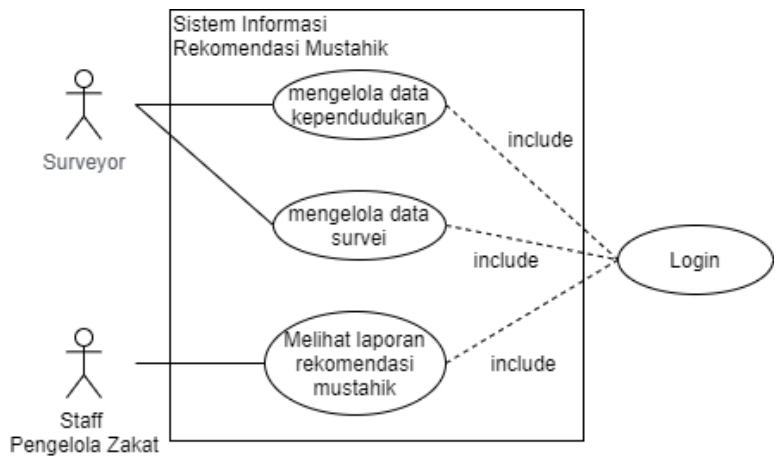

Gambar 3. Use Case Diagram Sistem Informasi

\section{B. Proses KDD}

Proses Knowledge Discovery in Databases (KDD) adalah proses yang terorganisir untuk mengidentifikasi pola valid, baru, berguna, dan dapat dimengerti dari kumpulan data besar dan kompleks[7]. Proses KDD dapat dilihat pada Gambar 4 mulai dari pemilihan atribut data hingga terciptalah sebuah pengetahuan.

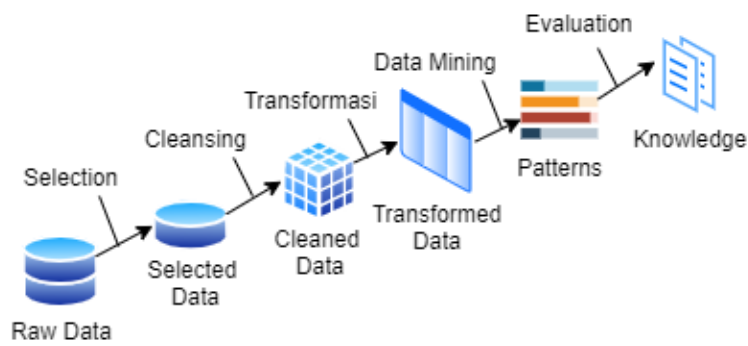

Gambar 4. Sekilas Langkah-langkah Susunan Proses KDD

\section{Data Selection}

Pada tahap ini data yang digunakan adalah data mustahik yang diperoleh dari hasil survei Badan Amil Zakat Nasional (BAZNAS) di tahun 2018. Pada penelitian ini berdasarkan data yang diberikan oleh BAZNAS, parameter yang digunakan yaitu : umur kepala keluarga, pekerjaan kepala keluarga, rata-rata pendapatan keluarga dalam satu bulan, jumlah tanggungan, keadaan tempat tinggal, kepemilikan tempat tinggal, tempat pembuangan kotoran, pola Makan. 


\section{Cleansing}

mengecek jika terdapat data duplikat atau parameter yang tidak memiliki nilai.

\section{Transformasi}

Dari parameter yang penulis telah seleksi terdapat parameter dengan nilai yang berbentuk kualitatif pada data mustahik seperti pekerjaan kepala keluarga, keadaan, dan kepemilikan tempat tinggal, dan WC. Oleh karena harus dilakukan proses inisialisasi data terlebih dahulu terhadap paramter tersebut ke dalam bentuk angka/numerikal. Setelah inisialisasi data, akan dilakukan metode min-max normalization (scalling) pada semua paramater untuk mendapatkan nilai range nol hingga satu.

\section{Data mining menggunakan algoritma Artificial} Neural Network (ANN)

Pada tahap ini, metode yang digunakan adalah klasifikasi dengan algoritma artificial neural network. ANN digunakan karena memiliki ide dasar dari mengadopsi mekanisme berpikir sebuah sistem atau aplikasi yang menyerupai otak manusia, baik untuk pemrosesan berbagai sinyal elemen yang diterima, toleransi terhadap kesalahan/error, dan juga parallel processing. Oleh karena itu dengan memanfaatkan ANN diharapkan dapat membantu dalam menentukan rekomendasi mustahik.

Secara umum algoritma artificial neural network memiliki tahapan umum sebagai berikut:

1. Menginisialisasi bobot awal dengan nilai acak yang sangat kecil. Tentukan maksimum epoch, target error, dan learning rate $(\alpha)$.

2. Propagasi maju (forward propagation)

Propagasi maju mangacu pada kalkulasi untuk setiap node dari input layer hingga output layer. Bentuk persamaan untuk mendapatkan nilai node bisa dilihat pada persamaan (1).

$$
z_{-} i n_{j}=V_{o j}+\sum_{i=1}^{n} X_{i} V_{i j}
$$

Dimana:

$X_{i}$ : nilai node ke-i

$V_{i j}$ : nilai bobot ke-i

$V_{o j}$ : nilai bias pada node

Hasil dari nilai node akan digunakan sebagai nilai pada fungsi aktivasi seperti pada persamaan (2).

$$
z_{j}=f\left(z_{-} i n_{j}\right)
$$

Biasanya fungsi aktivasi yang digunakan adalah sigmoid, kemudian mengirimkan sinyal tersebut ke semua output.

3. Propagasi mundur (backpropagation)

Backpropagation adalah proses menghitung mundur semua bobot dari error output sampai kembali ke input menggunakan fungsi derivatif dari fungsi aktivasinya. Bentuk persamaan untuk menghitung error dapat dilihat pada persamaan (3).
Sebelum proses data mining dilakukan, diperlakukan cleansing terlebih dahulu untuk

$$
\delta_{k}=\left(t_{k}-y_{k}\right) f^{\prime}\left(z_{-} i n_{j}\right)
$$

Dimana:

$t_{k}:$ nilai output sebenarnya

$y_{k}$ : nilai output yang didapatkan

$f^{\prime}$ : turunan dari fungsi aktivitas

Hasil dari penghitungan error akan digunakan sebagai nilai koreksi bobot atau bias seperti pada persamaan (4).

$$
\Delta w_{j k}=\delta_{k} X_{i}
$$

4. Perubahan bobot dan bias

Pada tahap ini nilai bobot dan bias disetiap node akan diubah seperti perasamaan (5).

$$
w_{j k}(\text { new })=w_{j k}(\text { old })+\Delta w_{j k}
$$

5. Ulangi tahap 2 sampai 4 untuk setiap data dan selama jumlah epoch masih lebih kecil dari nilai maksimal.

Sistem ini dibangun memanfaatkan data mustahik dari BAZNAS SULSEL. Data disimpan dalam file dengan format Comma Delimited (CSV). Data yang digunakan adalah data hasil min-max normalization agar data memilliki range yang sama, yaitu nol sampai dengan satu.

Sebelum training, data akan dibagi secara acak menggunakan $k$-fold cross validation untuk menentukan data latih dan data uji. K-fold cross validation merupakan prosedur pengambilan sampel ulang yang digunakan untuk mengevaluasi model machine learning pada data sample terbatas [8]. Cara kerja K-fold cross validation yaitu dengan mengelompokkan data latih dengan data uji yang saling terpisah, kemudian melakukan proses pengujian yang diulang sebanyak K kali.

Langkah dari K-fold cross validation antara lain:

1. Mengocok data secara acak

2. Membagi data yang tersedia menjadi $\mathrm{K}$ kelompok.

3. Setiap K dibuat sejumlah $\mathrm{T}$ himpunan data yang memuat semua data latih yang berada di kelompok ke-K.

4. Mengerjakan algoritma yang dimiliki dengan sejumlah $\mathrm{T}$ data latih.

5. Pengujian algoritma menggunakan data kelompok K sebagai data uji.

6. Melakukan pencatatan hasil algoritma.

Langkah pertama dalam training ANN yaitu menentukan jumlah neuron pada hidden layer, menentukan nilai learning rate dan jumlah epoch. Kemudian data training di latih untuk mengenal pola dengan cara penyesuaian nilai bobot dan bias secara berulang. Perulangan akan dihentikan ketika nilai epoch dan k-fold telah tercapai.

Untuk menentukan kualitas sebuah model dapat dilihat dari nilai Mean Squared Error (MSE) guna mengetahui tingkat kesalahan yang memiliki tujuan 
untuk mengetahui seberapa optimal metode dapat menghasilkan solusi dari suatu permasalahan pada saat

\section{Interpretation/Evaluation}

Pada tahap ini data mining akan diuji untuk mendapatkan model yang dapat digunakan pada sistem infomasi mustahik.

C. Implementasi dan Pengujian Sistem

Pada tahap ini akan diterapkan semua yang telah direncanakan dalam desain dan perancangan sebelumnya. Tahap ini juga akan menentukan keberhasilan sistem yang akan dibangun. Pengujian dibagi menjadi dua bagian yaitu, pengujian data mining dan implementasi sistem informasi.

Pengujian data mining dilakukan dengan skenario berikut:

1) Pengujian pengaruh kombinasi nilai learning rate dari 0.1 sampai 1.0 dan jumlah neuron pada hidden layer dari dua sampai tujuh.

2) Pengujian pengaruh jumlah epoch terhadap nilai MSE dan akurasi. Pengujian dilakukan dengan mengubah epoch dari 40 sampai 200.

3) Pengujian pengaruh jumlah K pada k-fold cross validation terhadap nilai akurasi dan MSE dengan menggunakan kombinasi nilai learning rate dan jumlah hidden layer. Pengujian dilakukan dengan mengubah Jumlah K dari 6 sampai 10.

Pengujian sistem penentuan rekomendasi mustahik dilakukan dengan cara mengamati output dari berbagai masukan dan membandingkan output aplikasi yang dibangun dengan output yang dilihat oleh pengguna sehingga sesuai dengan tujuan yang akan dicapai pada penelitian ini.

\section{HASIL DAN PEMBAHASAN}

\section{A. Pengujian Data Mining}

Data yang digunakan untuk training model mustahik adalah BAZNAS Sulawesi Selatan tahun 2018. Pengujian pertama dilakukan untuk mengetahui nilai MSE hasil kombinasi learning rate dan jumlah neuron hidden layer dengan kondisi awal yaitu: jumlah fold 6 dan epoch 120.

Tabel 1. Nilai MSE Pengujian Kombinasi Learning Rate dan Jumlah Neuron Hidden Layer

\begin{tabular}{|c|c|c|c|c|c|c|}
\hline \multirow[b]{2}{*}{ L. Rate } & \multicolumn{6}{|c|}{ MSE } \\
\hline & $\begin{array}{c}\text { N.H. } \\
2\end{array}$ & $\begin{array}{c}\text { N.H. } \\
3\end{array}$ & $\begin{array}{c}\text { N.H. } \\
4\end{array}$ & $\begin{array}{c}\text { N.H. } \\
5\end{array}$ & $\begin{array}{c}\text { N.H. } \\
6\end{array}$ & N.H.7 \\
\hline 0.1 & 0.062 & 0.060 & 0.060 & 0.060 & 0.060 & 0.061 \\
\hline 0.2 & 0.057 & 0.056 & 0.056 & 0.055 & 0.055 & 0.054 \\
\hline 0.3 & 0.055 & 0.053 & 0.053 & 0.052 & 0.051 & 0.051 \\
\hline 0.4 & 0.054 & 0.051 & 0.051 & 0.050 & 0.049 & 0.049 \\
\hline 0.5 & 0.053 & 0.050 & 0.048 & 0.048 & 0.046 & 0.048 \\
\hline 0.6 & 0.052 & 0.049 & 0.048 & 0.046 & 0.043 & 0.046 \\
\hline 0.7 & 0.052 & 0.049 & 0.049 & 0.044 & 0.040 & 0.044 \\
\hline 0.8 & 0.051 & 0.048 & 0.049 & 0.043 & 0.040 & 0.043 \\
\hline
\end{tabular}

training dan akurasi rata-rata dari seluruh round sebagai acuan performansi algoritma pada data uji

\begin{tabular}{ccccccc}
\hline & \multicolumn{6}{c}{ MSE } \\
\cline { 2 - 7 } L. Rate & N.H. & N.H. & N.H. & N.H. & N.H. & \multirow{2}{*}{ N.H.7 } \\
& 2 & 3 & 4 & 5 & 6 & \\
\hline 0.9 & 0.051 & 0.048 & 0.048 & 0.041 & 0.045 & 0.040 \\
1.0 & 0.050 & 0.048 & 0.047 & 0.040 & 0.040 & 0.038 \\
\hline
\end{tabular}

Dari Tabel 1 terlihat bahwa pada saat nilai learning rate 0.1 hingga 0.5 , nilai MSE tidak mengalami perubahan yang besar terhadap jumlah neuron hidden layer. Adapun untuk nilai learning rate 0.6 sampai 1.0, nilai MSE mengalami fluktuitasi. Untuk nilai MSE terendah berada saat jumlah neuron hidden layer bernilai tujuh dengan learning rate 1.0 dan nilai MSE tertinggi berada saat jumlah neuron hidden layer bernilai dua dengan learning rate 0.1 .

Dari hasil pengujian ini, neuron hidden layer yang memiliki nilai rata-rata MSE terendah yaitu berjumlah enam akan digunakan untuk melihat pengaruh perubahan jumlah epoch terhadap nilai MSE dan akurasi terhadap data uji.

Tabel 2. Nilai MSE pengujian variasi jumlah epoch dan learning rate untuk neuron hidden layer berjumlah enam

\begin{tabular}{cccccc}
\hline \multirow{2}{*}{ L. Rate } & \multicolumn{5}{c}{ MSE } \\
\cline { 2 - 6 } 0.1 & E. 40 & E. 80 & E. 120 & E. 160 & E. 200 \\
\hline 0.2 & 0.067 & 0.062 & 0.060 & 0.058 & 0.056 \\
0.3 & 0.061 & 0.058 & 0.055 & 0.052 & 0.050 \\
0.4 & 0.059 & 0.052 & 0.049 & 0.046 & 0.043 \\
0.5 & 0.056 & 0.050 & 0.046 & 0.042 & 0.040 \\
0.6 & 0.055 & 0.049 & 0.043 & 0.039 & 0.037 \\
0.7 & 0.055 & 0.049 & 0.040 & 0.022 & 0.020 \\
0.8 & 0.055 & 0.049 & 0.040 & 0.037 & 0.035 \\
0.9 & 0.055 & 0.051 & 0.045 & 0.027 & 0.042 \\
1.0 & 0.056 & 0.050 & 0.040 & 0.036 & 0.037 \\
\hline
\end{tabular}

Untuk hasil pengujian nilai MSE dapat dilihat pada Tabel 2, dimana diperoleh nilai MSE mengalami penurunan saat nilai epoch dinaikkan. Penurunan nilai MSE semakin besar saat learning rate dinaikkan, namun ketika learning rate bernilai 0.9 terjadi peningkatan nilai MSE disaat epoch berjumlah 200.

Tabel 3. Nilai akurasi rata-rata pengujian variasi jumlah epoch dan learning rate saat neuron hidden layer berjumlah enam

\begin{tabular}{cccccc}
\hline \multirow{2}{*}{ L. Rate } & \multicolumn{5}{c}{ Akurasi Rata-rata } \\
\cline { 2 - 6 } & E. 40 & E. 80 & E. 120 & E. 160 & E. 200 \\
\hline 0.1 & $83.3 \%$ & $86.6 \%$ & $87.5 \%$ & $87.0 \%$ & $87.5 \%$ \\
0.2 & $84.5 \%$ & $86.2 \%$ & $87.5 \%$ & $87.0 \%$ & $86.6 \%$ \\
0.3 & $87.0 \%$ & $86.6 \%$ & $87.9 \%$ & $87.0 \%$ & $87.9 \%$ \\
0.4 & $86.6 \%$ & $88.7 \%$ & $89.1 \%$ & $87.5 \%$ & $88.3 \%$ \\
0.5 & $86.6 \%$ & $89.1 \%$ & $88.3 \%$ & $86.6 \%$ & $87.9 \%$
\end{tabular}




\begin{tabular}{|c|c|c|c|c|c|c|c|c|c|c|c|}
\hline \multirow{2}{*}{ L. Rate } & \multicolumn{5}{|c|}{ Akurasi Rata-rata } & \multirow{2}{*}{ L. Rate } & \multicolumn{5}{|c|}{ Akurasi Rata-rata } \\
\hline & E. 40 & E. 80 & E. 120 & E. 160 & E. 200 & & E. 40 & E. 80 & E. 120 & E. 160 & E. 200 \\
\hline 0.6 & $85.8 \%$ & $88.7 \%$ & $87.5 \%$ & $88.3 \%$ & $88.7 \%$ & 0.7 & $86.2 \%$ & $88.3 \%$ & $87.9 \%$ & $87.5 \%$ & $90.4 \%$ \\
\hline
\end{tabular}$$
0.8
$$$$
86.6 \% \quad 87.5 \% \quad 86.2 \% \quad 87.9 \% \quad 89.1 \%
$$$$
\begin{array}{llllll}
0.9 & 86.6 \% & 87.5 \% & 87.9 \% & 87.9 \% & 88.7 \%
\end{array}
$$$$
\begin{array}{llllll}
1.0 & 86.2 \% & 87.0 \% & 87.9 \% & 87.0 \% & 90.8 \%
\end{array}
$$

Tabel 3 memperlihatkan hasil pengujian nilai akurasi rata-rata terhadap jumlah epoch. Akurasi yang diperoleh meningkat saat nilai epoch di naikkan dari 40 ke 80 kecuali untuk learning rate 0.3. Adapun saat nilai epoch di naikkan ke 120 dan 160 akurasi mengalami fluktuasi dan mengalami peningkatan saat nilai epoch 200.

Untuk pengujian selanjutnya kombinasi learning rate $1.0 \mathrm{~d}$ an epoch 200 akan digunakan sebagai tambahan kondisi karena memiliki nilai akurasi tertinggi dengan nilai MSE yang cukup rendah.

Tabel 4. Akurasi dan MSE pengujian jumlah fold

\begin{tabular}{ccc}
\hline k-fold & MSE & Akurasi Rata-rata \\
\hline 6 & 0.037358 & $90.833 \%$ \\
7 & 0.040509 & $92.089 \%$ \\
8 & 0.02232 & $91.25 \%$ \\
9 & 0.029284 & $89.126 \%$ \\
10 & 0.038734 & $90.417 \%$ \\
\hline
\end{tabular}

Berdasarkan hasil pengujian pada Tabel 4 diperoleh nilai MSE tertinggi pada saat jumlah fold bernilai tujuh dan terendah saat bernilai sembilan. Adapun akurasi terbaik yaitu $92.089 \%$ diperoleh dengan jumlah fold tujuh dan terendah saat jumlah fold bernilai Sembilan.

\begin{tabular}{cc} 
Tabel 5. Model training mustahik \\
\hline Nama & Nilai \\
\hline k-fold & 7 \\
n_hidden & 6 \\
Epoch & 200 \\
Learning rate & 1.0 \\
\hline
\end{tabular}

Dari pengujian yang telah dilakukan didapat model training seperti pada Tabel 5 untuk digunakan pada sistem informasi mustahik.

\section{B. Pengujian Sistem Informasi}

Sistem informasi mustahik dibuat menggunakan platform website yang digunakan sebagai wadah bagi user untuk menginput data survei dan melihat hasil algoritma artificial neural network dalam penentuan rekomendasi mustahik. Berikut adalah tampilan interface dari aplikasi website:

\section{Halaman Login}

Halaman Login merupakan halaman awal yang diakses dan diperuntukkan bagi user. Jika username dan password yang dimasukkan benar maka user akan masuk ke halaman Dashboard. Jika password salah maka user tidak akan dapat masuk ke halaman Dashboard hingga user memasukkan username dan password yang benar.

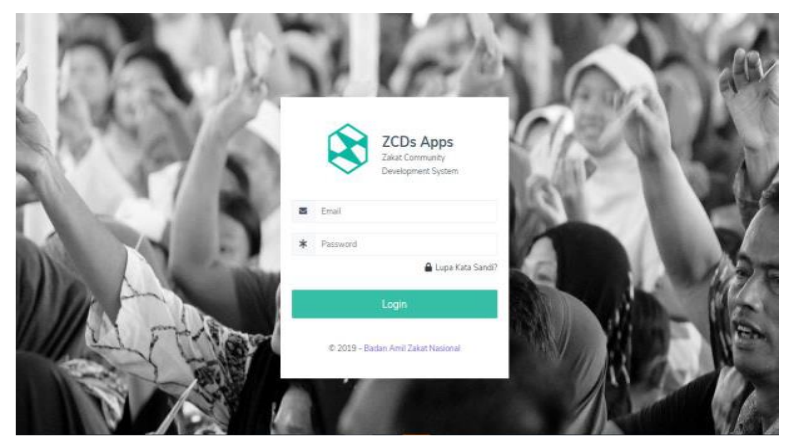

Gambar 5. Tampilan Halaman Login User

\section{Halaman Dashboard}

Halaman Dashboard merupakan halaman awal dari aplikasi web untuk visualisasi data mustahik. Pada halaman dashboard ditampilkan jumlah seluruh data keluarga, penduduk, dan desa terdaftar.

Pada halaman dashboard juga terdapat data mustahik yang direkomendasikan di suatu daerah pada tahun tertentu, dimana memiliki fitur untuk search, yang bisa digunakan user untuk melakukan pecarian berdasarkan kecamatan dan tahun survei dilakukan.

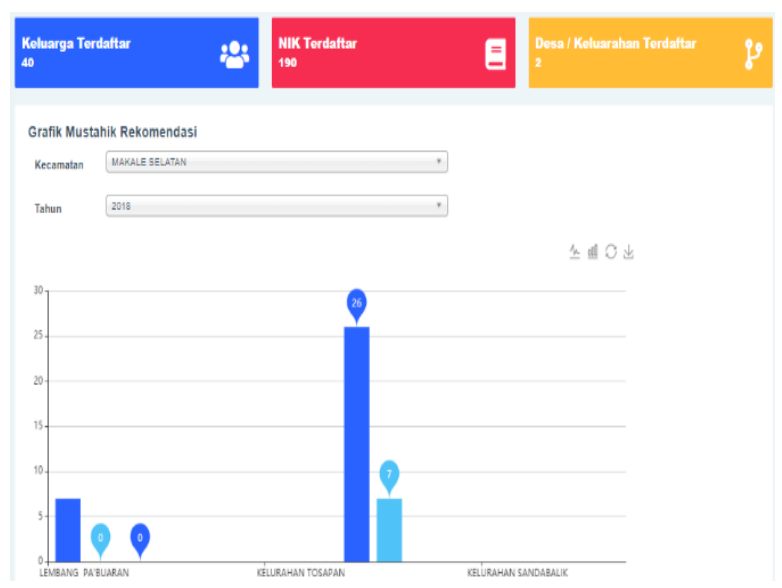

Gambar 6. Tampilan halaman Dasboard

\section{Halaman Kartu Keluarga}

Halaman Kartu Keluarga merupakan halaman untuk melihat, menambah, mengubah, dan menghapus daftar kartu keluarga.

Pada halamam kartu keluarga terdapat fitur cari data, yang bias digunakan user untuk melakukan pencarian data kartu keluarga berdasarkan nomor kartu keluarga, provinsi, kota, kecamatan, dan kelurahan. 

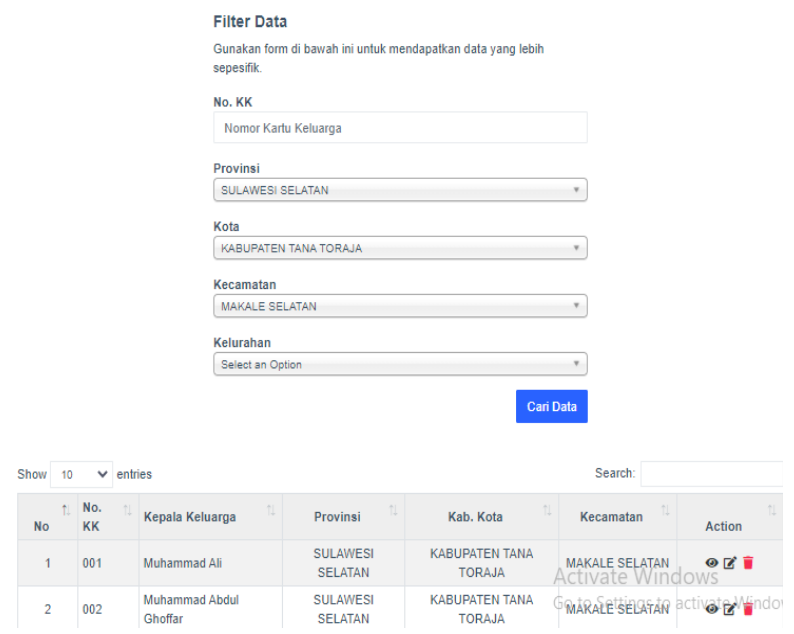

Gambar 7. Tampilan halaman indeks kartu keluarga

4. Halaman Anggota Keluarga

Halaman Kartu Keluarga merupakan halaman untuk melihat, menambah, mengubah, dan menghapus daftar kartu keluarga.

Pada halamam kartu keluarga terdapat fitur cari data, yang bias digunakan user untuk melakukan pencarian data kartu keluarga berdasarkan nomor kartu keluarga, provinsi, kota, kecamatan, dan kelurahan.
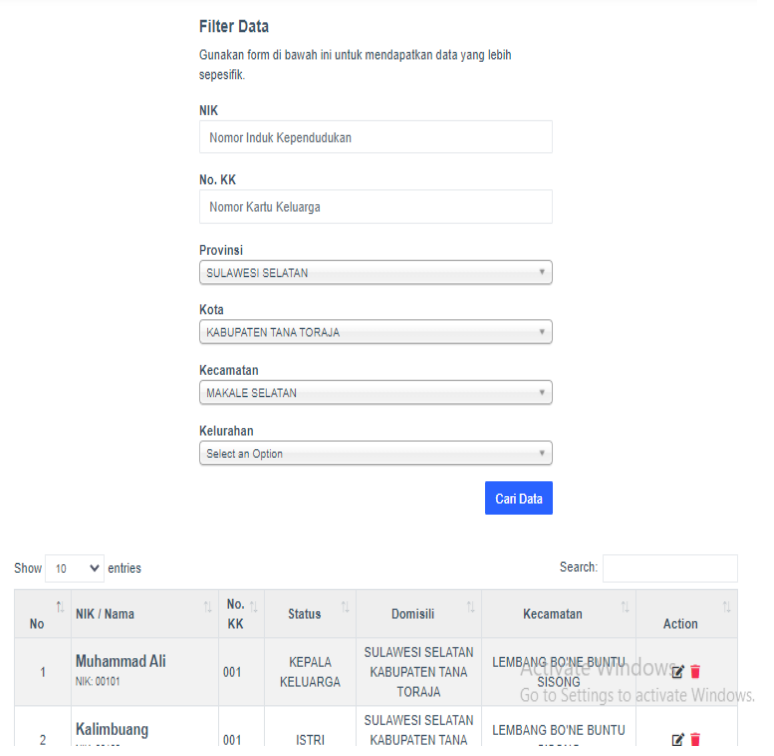

Gambar 8. Tampilan halaman indeks anggota keluarga

\section{Halaman Form Sensus}

Halaman Form Sensus merupakan halaman untuk melihat dan membuat data survei terhadap keluarga yang telah terdaftar pada sistem informasi. Dimana terdapat fitur untuk cari data, yang bisa di gunakan user untuk melakukan pencarian daftar keluarga berdasarkan nomor kartu keluarga, provinsi, kota, kecamatan, dan kelurahan.
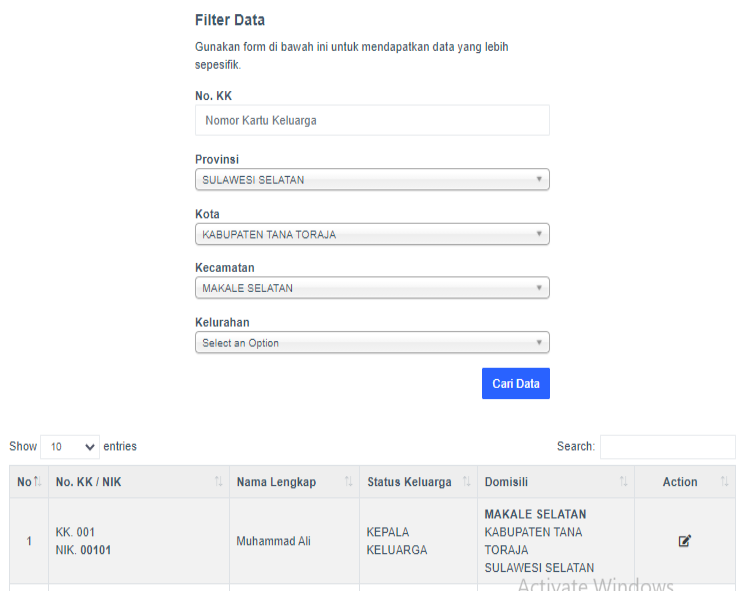

Gambar 9. Tampilan halaman indeks form sensus

Halaman Form Sensus untuk membuat data suvei, data di simpan pada table program_mustahik yang kemudian men-trigger API pada aplikasi data mining untuk mengklasifikasi data untuk disimpan kembali pada database.

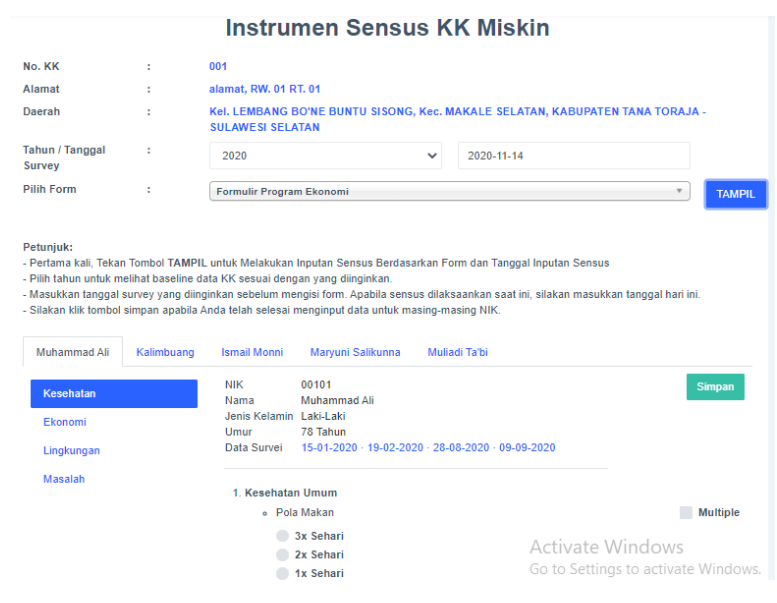

Gambar 10. Tampilan halaman form sensus mustahik

6. Halaman Laporan Rekomendasi

Halaman Laporan Rekomendasi merupakan halaman untuk melihat hasil klasifikasi data minig, dimana hasil klasifikasi di urutkan dari nilai tertiggi.

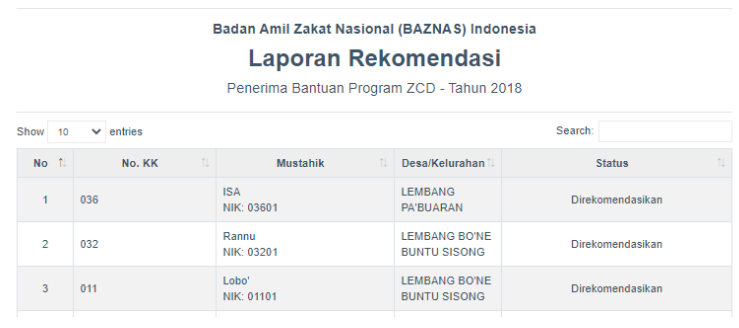

Gambar 11. Tampilan halaman laporan rekomendasi

Halaman ini memiliki tiga jenis filter untuk memudahkan pengguna mencari informasi spesifik yang diinginkan. Filter yang tersedia adalah filter 
provinsi hingga kelurahan/desa, tahun, dan nomor kartu keluarga.

\section{IV.KESIMPULAN}

Berdasarkan hasil pengujian pada penelitian ini dapat disimpulkan bahwa data mining menggunakan algoritma artificial neural network dapat menghasilkan akurasi rata-rata yang baik yaitu, $92.09 \%$ pada saat jumlah neuron hidden layer bernilai enam, learning rate bernilai satu, fold tujuh, dan epoch bernilai 200. Untuk sistem informasi, user dapat melakukan penginputan data kependudukan dan sensus mustahik,

\section{REFERENSI}

[1] Data dan Informasi Kemiskinan Sulawesi Selatan 2017. Makassar: BPS Provinsi Sulawesi Selatan, 2018.

[2] Data dan Informasi Kemiskinan Sulawesi Selatan 2016. Makassar: BPS Provinsi Sulawesi Selatan, 2017.

[3] Kementerian Agama RI, Panduan Zakat Praktis, vol. 53, no. 9. Kementerian Agama Republik Indonesia, 2013.

[4] A. Fadli, "Konsep Data Minning," IlmuKomputer.Com, 2011. http://ilmukomputer.org/2011/03/14/konsep-dataminning/ (accessed Nov. 26, 2018).

[5] H. Annur, "Klasifikasi Masyarakat Miskin Menggunakan merekomendasikan mustahik dalam bentuk grafik dan membuat laporan rekomendasi mustahik berdasarkan nilai klasifikasi tertinggi.

\section{UCAPAN TERIMA KASIH \\ (ACKNOWLEDGEMENT)}

Penulis mengucapkan terima kasih kepada Allah SWT, kedua orang tua, keluarga, kedua dosen pembimbing, seluruh dosen Teknik Elektro khususnya program studi D4 Teknik Komputer dan Jaringan dan teman-teman se-program studi TKJ angkatan 2015.

Metode Naive Bayes," Ilk. J. Ilm., vol. 10, no. 2, pp. 160165,2018

[6] A. Wanto, "Penerapan Jaringan Saraf Tiruan Dalam Memprediksi Jumlah Kemiskinan," Kumpul. J. Ilmu Komput., vol. 05, no. 01, pp. 61-74, 2018.

[7] O. Maimon and L. Rokach, "Introduction to knowledge discovery in database," Eur. Tel-Aviv - Data Min. Knowl. Discov. Handb., pp. 1-17, 2005.

[8] J. Browniee, "A Gentle Intoduction to k-fold CrossValidation," 2018. https://machinelearningmastery.com/kfold-cross-validation (accessed Dec. 03, 2020). 